\title{
AS DISPUTAS E A LÓGICA FRAGMENTÁRIA: NOVAS RELAÇÕES ENTRE ESPAÇOS PÚBLICOS E PRIVADOS EM CHAPECÓ - SC
}

Pós-doutorando no Laboratório "Grupo de Pesquisa Produção do Espaço e Redefinições Regionais" (GAsPERR), Universidade Estadual Paulista (UNESP), Campus Presidente Prudente. Pesquisador do Projeto Temático: "Fragmentação socioespacial e urbanização brasileira: escalas, vetores, ritmos, formas e conteúdos -

FragUrb" (Fapesp: 2018 - 2023). pablomartinbender@gmail.com

Eda Maria Góes Professora da Universidade Estadual Paulista (UNESP), Campus Presidente Prudente. Membro do GAsPERR "Grupo de Pesquisa Produção do Espaço e Redefinições Regionais" e pesquisadora do Projeto Temático "Fragmentação socioespacial e urbanização brasileira: escalas, vetores, ritmos, formas e conteúdos - FragUrb"

(Fapesp: 2018 - 2023). eda.goes@unesp.br

\begin{abstract}
RESUMO
Neste artigo são discutidas as novas relações entre espaços públicos e espaços privados estabelecidas a partir da revisão do Plano Diretor de Chapecó, em 2006, e seus impactos. Se verificaram uma série de ações e leis tendentes a afastar os jovens, principalmente os das periferias, do centro de Chapecó, além de normas e programas da prefeitura que promovem e regulamentam a expansão dos interesses comerciais e empresariais sobre a gestão do espaço público. Mas também se observou os limites desses programas e as novas práticas espaciais dos jovens no centro, evidenciando mudanças nas relações entre público e privado. Se conclui que tendências como a privatização estão presentes, dentre outras que configuram o processo de fragmentação socioespacial, mas há disputa.
\end{abstract}

Palavras chave: Fragmentação Socioespacial. Jovens. Temporalidades diferenciadas.

\section{DISPUTES AND FRAGMENTARY LOGIC: NEW RELATIONS BETWEEN PUBLIC AND PRIVATE SPACES IN CHAPECÓ - SC}

\begin{abstract}
This article discusses the new relations between public and private spaces established from the revision of the Master Plan for Chapecó (Santa Catarina state, southern Brazil) in 2006 and its impacts. There have been a series of actions and laws aimed at removing young people, especially those from the peripheries, from the centre of Chapecó, In addition to a series of municipal norms and programs that promote and regulate the expansion of commercial and business interests over the management of public space. But we also observed the limits of these programs and the new spatial practices of young people in the center, evidencing changes in relations between public and private. We concluded that trends such as privatization are present, among others that constitute the process of socio-spatial fragmentation, but there is a dispute.
\end{abstract}

Keywords: Socio-spatial Fragmentation. Young people. Differentiated temporalities.

\section{INTRODUÇÃO}

Neste artigo busca-se refletir sobre a produção do espaço público, com especial atenção às práticas espaciais observadas, aos conflitos que nele se desencadeiam e às normas que regulamentam seu uso e gestão, tendo como referência empírica a cidade média de Chapecó, em Santa Catarina ${ }^{1}$. Com uma população total estimada de 224.013 habitantes em 2020, Chapecó se destaca como o principal centro urbano do Oeste Catarinense, devido principalmente à presença de importantes unidades

${ }^{1}$ Essa pesquisa se insere no âmbito Projeto Temático FragUrb, que envolve nove cidades, dentre as quais, Chapecó; e foi financiada pela Fundação de Amparo à Pesquisa do Estado de São Paulo (FAPESP). Processos: 2019/04430-6 e 2018/07701-8.

$\begin{array}{llllll}\text { Caminhos de Geografia } & \text { Uberlândia-MG } & \text { v. 23, n. } 85 & \text { fev./2022 } & \text { p. 54-68 } & \text { Página } 54\end{array}$


processadoras de produtos alimentícios (sobretudo de origem suína e avícola), que integram uma ampla gama de atividades econômicas e de serviços.

As características do processo de urbanização levaram à estruturação de um espaço urbano desigual. Por um lado, apresenta uma variedade de subespaços nos quais as condições de vida são precárias e instáveis, localizados principalmente na periferia da cidade (MATIELLO, et. al., 2017), área onde também se registra o maior déficit quantitativo e qualitativo de espaços públicos (MAIA, SILVA, ALMEIDA; 2019; RAMMÉ, 2014). Por outro, Chapecó conserva um centro dinâmico, habitado pela classe média e alta (MATTIANELLO, et. al. 2017) que, segundo um depoimento obtido em entrevista,"sofre com o barulho e a confusão nos finais de semana"2. Nesta área se localizam numerosos bares, casas noturnas e restaurantes, voltados ao público das mesmas classes. Mas o tamanho da cidade torna acessível o espaço público central para jovens provenientes das periferias, principalmente nos sábados e domingos, com suas práticas espaciais não previstas por comerciantes e incorporadores imobiliários. Neste artigo, analisamos questões referentes a essa dinâmica de lazer, os conflitos decorrentes, as normas que procuram afastar os jovens do centro e àquelas que revelam novas relações entre espaço público e espaço privado em Chapecó.Também examinamos a legislação municipal recente que estimula parcerias entre agentes privados e públicos na manutenção e produção de espaços públicos.

A fim de produzir material que pudesse auxiliar no levantamento de hipóteses e resultados preliminares de pesquisa, em novembro de 2019 foi realizado um trabalho de campo na cidade, conjuntamente com parte da equipe de pesquisadores do Projeto Temático "Fragmentação Socioespacial e Urbanização Brasileira: Escalas, Vetores, Ritmos, Formas e Conteúdos" (FragUrb) 3 . Nessa ocasião, observamos e fotografamos espaços públicos centrais e periféricos, focando no estado da infraestrutura mobiliária urbana e nas práticas cotidianas. Também foi efetuado um levantamento de informações e dados sobre Chapecó, aplicadas enquetes a usuários de espaços públicos e realizadas entrevistas com "agentes bem informados"4. Estava previsto para o mês de abril de 2020 um segundo trabalho de campo, mas a emergência da pandemia do Covid-19 direcionou a pesquisa para a utilização de novas ferramentas metodológicas, viáveis nesse novo contexto. Assim, a investigação foi se apoiando e desenvolvendo com base no material já levantado em campo, no aprofundamento da revisão bibliográfica e em informações, entrevistas e notícias passiveis de serem realizadas ou obtidas online e via internet.

Com base nesse material, se considerou adequado fazer um recorte espacial e analítico do espaço público de Chapecó, focando principalmente em duas problemáticas inter-relacionadas. Por um lado, no processo de "ocupação" do estacionamento da Havan, e nas disputas socioespaciais em torno da Avenida Getúlio Vargas, que têm os jovens, donos de bares e agentes da polícia como protagonistas. Por outro, chamou nossa atenção uma série de (novas) relações entre espaço público - espaço privado, estabelecidas através de leis municipais que abrem brechas para a gestão e a produção privada do espaço público. Tais relações afetam mais diretamente espaços centrais e pericentrais, mas têm alcance potencialmente mais amplo, conforme discutimos neste texto.

O artigo tem como objetivo analisar as relações entre espaço público e espaço privado resultantes destas "parcerias" formais e informais, em torno do uso e das disputas sobre o espaço público em Chapecó. O foco recai nas práticas espaciais e nos seus sujeitos e agentes, através dos quais se busca inserir tais relações no contexto mais amplo da produção do espaço urbano, atentando para as tendências à fragmentação socioespacial propostas pelo Projeto Temático FragUrb, observadas partir do aprofundamento da diferenciação nas cidades brasileiras, cuja origem se vincula à predominância de lógicas e subjetivações neoliberais que se antepõem à ideia de direito à cidade. $O$ recorte temporal se situa a partir do ano de 2006, quando teve lugar a revisão do Plano Diretor de Chapecó sob governo de um partido político conservador, que cedeu influência ao capital imobiliário na condução da política urbana e minou as bases populares do plano elaborado em 2004 (HASS, 2017). Como veremos, neste novo contexto, espaços públicos foram destruídos, a repressão policial foi intensificada e novas leis foram criadas, ao mesmo tempo em que surgiram algumas formas de resistência a tais processos.

É importante destacar que as considerações e discussões que são propostas não possuem a pretensão de serem definitivos, senão que têm como objetivo formular interpretações e descrever tendências

Entrevista online realizada com moradora de condomínio vertical do bairro Presidente Médici (Chapecó - SC), em 5 de julho de 2020, realizada por Natália Sá Brito e Pablo Bender.

${ }^{3}$ Esse projeto visa compreender, no plano da cidade e do urbano, como a lógica socioespacial fragmentária altera o conteúdo da diferenciação e das desigualdades, redefinindo os sentidos do direito à cidade.

${ }^{4}$ No Projeto Temático FragUrb, são considerados agentes bem informados àqueles que têm condições de fornecer informações sobre um dos temas abordados, seja pela função que desempenham, pela experiência etc.
Caminhos de Geografia
Uberlândia-MG
v. 23, n. 85
fev./2022
p. 54-68
Página 55 
acerca do espaço público de Chapecó,que poderão ser corroboradas ou não, uma vez que a pesquisa está em andamento.

\section{SOBRE O ESPAÇO PÚBLICO E O PROCESSO DE FRAGMENTAÇÃO SOCIOESPACIAL}

Em primeiro lugar, devemos entender que "espaço público" é uma expressão polissêmica que designa, às vezes, a um espaço metafórico, e outras, a um espaço construído e concreto. Como espaço metafórico, é frequentemente utilizado como sinônimo de "esfera pública", conceito filosófico abstrato desenvolvido principalmente por Habermas e Arendt, e que faz referência a um âmbito democrático ideal, de consensos, resolução de conflitos e debates. Este âmbito comunicacional influenciaria a agenda política através da expressão pública de ideias e interesses comuns (HABERMAS, 2003; ARENDT, 2008). Na crítica de Deutsche (2018) a essa interpretação, existiriam na sociedade uma pluralidade de esferas públicas (e não uma única), com multiplicidade de interesses e conflitos que permeiam a estrutura política, econômica e social.

Como construído e concreto, o espaço público faz alusão ao espaço jurídico que forma parte do território de um Estado e que serve de nexo relacional com os espaços privados, ao mesmo tempo em que se contrapõe a eles sobre a base de uma dimensão legal diferente. Esta separação entre público e privado conforma uma das bases do Estado Moderno, se diferenciando desta maneira do Antigo Regime, no qual todo o território e os bens eram propriedade da Coroa (SABATIER, 2002). Baseados nesta interpretação, Duhau e Giglia utilizam o termo "espaço juridicamente público", para referir-se ao espaço urbano que não forma parte do espaço privado de casas, fábricas ou lojas, e que constitui o tecido conectivo que organiza a cidade e a experiência urbana (DUHAU e GIGLIA, 2008, p. 59). Questões relacionadas ao mobiliário urbano e ao planejamento, também fazem referencia à dimensão construída e concreta do espaço público. Segundo Gomes (2002), um enfoque geográfico acerca do espaço público deve considerar as relações existentes entre as duas dimensões: a construída/jurídica e a política e social.

A multiplicação de shopping centers, grandes lojas, clubes privados e condomínios fechados nas últimas décadas, tem precipitado mudanças na tradicional separação jurídica entre espaço público espaço privado, criando inclusive lacunas legais à hora de legislar sobre esses espaços (BLANCO, 2011). A privatização do espaço público, que é uma das dimensões deste processo,somada ao crescente avanço dos espaços voltados à circulação(especialmente dos veículos) e à predominância de práticas de consumo, têm gerado, segundo alguns autores, uma "crise" do espaço público (SENNETT, 1999, CALDEIRA, 2000) e inclusive a sua "destruição" (DAVIS, 1999). Já a perspectiva dialética de Crawford (2014), próxima a Lefebvre (2000) e ao conceito de terceiro espaço de Soja (1996), aponta para a necessidade de analisar as práticas sociais que são realizadas cotidianamente inclusive nos espaços presumivelmente "mortos" (SENNETT, 1999, p. 26), destinados à circulação ou estacionamentos de veículos. Segundo a autora, tais práticas têm a capacidade de gerar, ao longo do tempo, novos usos e resistências aos processos dominantes (CRAWFORD, 2014).

Por sua vez, Souza (2018) sugere que a "tese do fim dos espaços públicos" associada às cidades pósmodernas (principalmente dos EUA) e generalizada para cidades em todo o mundo, deve ser problematizada; assim, propõe a substituição da palavra "fim" (com sentido de finitude), pela expressão "fins", com sentido de "finalidades". Considera mais apropriado constatar a multiplicidade de novos usos e finalidades do espaço público, que decretar sua "decadência" ou "crise"; para ele, anunciar seu "fim" generalizado, é uma interpretação "drástica e pessimista", que não favorece a construção de possibilidades alternativas e novas interpretações (SOUZA, 2018, p. 203).

Trabalhos baseados em pesquisas empíricas focadas nas grandes metrópoles latino-americanas, como a Cidade do México, reinterpretam tal "crise" em termos da dissociação entre o espaço juridicamente público e as práticas da vida cotidiana, com base na constatação de que as classes médias e altas realizam cada vez com menos frequência este tipo de práticas no espaço público (DUHAU e GIGLIA, 2008, p. 59). Ainda segundo estes autores, as práticas cotidianas no espaço público estão permeadas por uma racionalidade, uma "ordem urbana", por vezes formal, por vezes informal, que as delimita, ao tempo em que as viabiliza, gerando nesse processo solidariedades, tensões e conflitos (DUHAU e GIGLIA, 2004, p. 262).

As normas informais de sociabilidade nos espaços públicos seriam aquelas implícitas, horizontais, não escritas, que atuam como acordos territoriais cotidianos, fazendo com que as pessoas ajustem seus comportamentos em público de maneira recíproca. Por um lado, nenhuma normativa ou regulamentação administrativa formal conseguiria substituir estas negociações informais e latentes, que são as que outorgam vitalidade e espontaneidade ao espaço público (DUHAU e GIGLIA, 2004;

$\begin{array}{llllll}\text { Caminhos de Geografia } & \text { Uberlândia-MG } & \text { v. 23, n. 85 } & \text { fev./2022 } & \text { p. 54-68 } & \text { Página } 56\end{array}$


ARAMBURO, 2008). Por outro lado, as normas formais que regulamentam as práticas no espaço público, estão relacionadas com o ordenamento legal que emana desde as diferentes instâncias do Estado, através do direito público.Tais normas estão orientadas "para a obtenção de interesses comuns" e, em teoria, representam "o princípio da supremacia do interesse público em face do interesse individual" (GUARANÁ, 2009, p. 2 e 3). Este princípio, expresso na Constituição Federal Brasileira, significa que, ocorrendo conflitos entre o interesse público e o interesse privado, deve de prevalecer o interesse público, isto é, aquele que atende um maior número de pessoas (GABARDO, 2017).

O controle dos aparelhos de coação e coerção permite ao Estado fazer cumprir as normas formais através do "monopólio legítimo da violência", brindando desta forma uma (aparente) distribuição equitativa da segurança no seu território (WEBER, [1918] - 1982). Nas últimas décadas, se tem produzido um intenso processo de "privatização da segurança" e uma "desconcentração do monopólio da violência do Estado", que vem acontecendo principalmente através da proliferação de empresas de segurança particular e da utilização de agentes públicos para realizar serviços de vigilância privada (SILVA, 2008, p. 12). Tal processo implica na problematização do reconhecimento da segurança como um direito, uma vez que passa a ser tratada como mercadoria. Além disso, esta problemática também está relacionada à expansão antes citada, de condomínios fechados e shopping centers, que agregam serviços e mecanismos de segurança e controle como um diferencial de consumo (SPOSITO e GÓES, 2013).

Neste sentido, no atual período técnico-científico-informacional (SANTOS, 1996), a "homogenização de espaços e pessoas se combina com esforços de diferenciação", veiculados e promovidos por agentes que adotam "estratégias de separação e controle em relação aos outros", afim de manter altos padrões de "segurança e status", enfraquecendo as relações entre os citadinos, pelas novas práticas espaciais que incorporam (SPOSITO e GÓES, 2013, p. 294 - 295). Esta racionalidade urbana é resultado de um processo de autossegregação que se intensifica, indicando que tanto as barreiras materiais, quanto as simbólicas e culturais, são dimensões que conformam o chamado processo de fragmentação socioespacial (PRÉVÔT-SCHAPIRA, 2001; SPOSITO e SPOSITO, 2020), presente inclusive em várias cidades médias brasileiras (SPOSITO e GÓES, 2013). O processo de fragmentação socioespacial ameaça o direito à diferença e à pluralidade, tão próprios da vida urbana, ao mesmo tempo em que aprofunda as desigualdades no que diz respeito ao acesso de serviços e espaços coletivos. Além disso, evidencia as díspares correlações de forças "que conduzem os destinos da cidade", a favor da reprodução do capital e contra o "direito à cidade" (SPOSITO e SPOSITO, 2020, p. 6; LEFEBVRE, 2001).

Segundo Magrini e Catalão (2019), a fragmentação socioespacial possui três dimensões indissociáveis: a produção do tecido urbano, as práticas espaciais e a constituição dos imaginários. Desta maneira, se bem os autores considerem que os enclaves fechados são sua condição mais evidente, a mesma não se restringe a esses espaços porque "há uma série de outros tipos de enclaves demarcados por barreiras mais fluídas, não raro apenas simbólicas, que estabelecem modos de ruptura e separação socioespacial no interior das cidades" (MAGRINI e CATALÂO, 2019, p. 142). Além disso, apontam para a necessidade de se considerar a expansão do consumo de espaços e bens materiais pelas classes populares em seu potencial de integração social e espacial, portanto, como atenuadores do processo de fragmentação socioespacial (MAGRINI e CATALÃO, 2019).

Como será analisado a seguir, embora, em princípio, o centro de Chapecó seja frequentado por diferentes classes sociais, ainda que por motivos diferentes, como trabalhar, morar, consumir, se divertir etc. ${ }^{5}$, conformando o que seria um espaço público democrático, existe nele uma "ordem urbana", exercida por normas e coações, que tentam homogeneizar o espaço, afastando os jovens, principalmente aqueles de baixa renda. Processos de destruição de infraestrutura pública, avanço do setor privado na produção do espaço público, por um lado,e "ocupação" coletiva por parte dos jovens de espaços privados de acesso coletivo, por outro, são algumas das evidências empíricas que nos permitem começar a refletir acerca da existência de novas relações entre espaço público -espaço privado na cidade de Chapecó.

\section{A AVENIDA GETÚLIO VARGAS E SUA MULTIFUNCIONALIDADE}

Chapecó apresenta na atualidade um acelerado processo de verticalização, principalmente no centro da cidade, habitat de classe média e alta, apesar da proliferação de alguns condomínios fechados de alto padrão na periferia, nos últimos anos (GROSSELI, 2020).

${ }^{5} \mathrm{Tal}$ como pudemos observar durante pesquisa de campo e com base no levantamento bibliográfico.

$\begin{array}{llllll}\text { Caminhos de Geografia } & \text { Uberlândia-MG } & \text { v. 23, n. } 85 & \text { fev./2022 } & \text { p. 54-68 } & \text { Página } 57\end{array}$


A Avenida Getúlio Vargas é a coluna vertebral, o "espaço público por excelência" (ANTUNES, 2009, p. 50 ), da cidade que nasceu planejada 6 e cujo traçado caracterizado por uma "ordenação cartesiana, ..., com avenidas largas, quadras bem definidas" deveria representar organização e potencial desenvolvimento (HASS, REI e BADALOTI, 2008, p.211 apud ANTUNES, 2009, p.11)

Com uma extensão de mais de $6 \mathrm{~km}$ de comprimento e largas calçadas a cada lado da via, que permitem a circulação fluída dos pedestres, seus canteiros centrais também são de dimensões consideráveis, bem arborizados, equipados com iluminação apropriada, gazebos de jardim, esculturas e monumentos. Nesta avenida é possível encontrar lojas, bares, restaurantes e foodtrucks para públicos de idade e condição econômica diversa, além das sedes de importantes instituições, como prefeitura, polícia civil, bombeiros, entre outras.

Em linhas gerais, a Avenida Getúlio Vargas apresenta usos multifuncionais. Além da circulação de pedestres, os edifícios residenciais se misturam com pequenos e médios comércios em área bem equipada de infraestrutura, o que caracteriza uma complexa área de intercâmbios sociais, conforme Jane Jacobs (1961) considerava adequado para um espaço urbano. Esta particular dinâmica social e espacial, torna a avenida atraente para aqueles que precisam realizar trâmites administrativos, fazer compras, consumir em seus bares e restaurantes ou simplesmente, se reunir com amigos para desfrutar um momento de lazer e sociabilidade.

O tamanho da cidade facilita os deslocamentos para a área central, como já mencionado, inclusive de transporte público ou bicicleta. Nas enquetes aplicadas no trabalho de campo ${ }^{7}, 85 \%$ dos participantes responderam que a Avenida Getúlio Vargas e o Ecoparque, eram seus espaços públicos favoritos e também os que mais frequentavam. Este dado, em que pese sua natureza qualitativa, além de revelar a importância da avenida na sociabilidade urbana, corrobora as considerações de Rammé (2014), Maia, Almeida e Silva (2019), sobre a carência de espaços públicos de lazer alternativos e a deficiente infraestrutura dos que estão localizados fora da área centrale pericentral de Chapecó.

Observações iniciais sobre as relações cotidianas na avenida poderiam nos indicar que estamos ante a presença de um espaço público plural e democrático, ideal, portanto, onde se produziriam encontros espontâneos com a diversidade e com desconhecidos, conforme proposição de Innerarity (2010) acerca das qualidades do espaço público na cidade moderna. Não obstante, como veremos em seguida, uma análise aprofundada das relações sociais que acontecem na Avenida Getúlio Vargas, revela processos e temporalidades diferenciadas na produção do espaço público, submetidos a uma rigorosa ordem urbana, que tenta restringir a diversidade social, em favor de determinados interesses econômicos, ao mesmo tempo em que produz resistências. Quando nos empregamos a expressão "temporalidades diferenciadas" na produção do espaço, fazemos referência aos períodos e/ou dias diferentes nos quais os grupos sociais realizam suas práticas espaciais de consumo e lazer num mesmo espaço, evitando convergir. Assim, por exemplo, na referida entrevista (nota 2), a citadina afirmou que prefere não ir ao centro nos sábados e domingos porque tem "muita confusão", enquanto que os jovens da periferia escolhem esses dias para aí realizar suas práticas de sociabilidade.

\section{OS JOVENS, O ESTACIONAMENTO DA HAVAN E AS PISTAS DE SKATE}

Os jovens, em todas as cidades, e principalmente os jovens das periferias, costumam fazer uso intenso do espaço público, pois eles, de forma geral, não têm dinheiro para gastar em atividades de lazer pagas, como baladas, bares e restaurantes, onde o consumo e a sociabilidade acostumam ter um alto preço. Em Chapecó, a realidade não é diferente. Há anos, centenas de jovens advindos de bairros distantes se congregam na Avenida Getúlio Vargas nos finais de semana para dar um passeio, "ver e ser vistos", e ocupar diversos pontos da avenida, às vezes, em torno de carros com som alto, gerando com estas práticas "tensões" com a polícia, com os donos de bares e restaurantes (ANTUNES, 2009; KESCHNER, 2017), e também com moradores, conforme sugerido pela entrevistada já citada (Nota 2).

Um dos espaços de sociabilidade escolhidos por esses jovens para encontros e prática de esportes "radicais", tem sido o estacionamento da loja $\operatorname{Havan}^{8}$, localizado sobre a avenida, na esquina com a

${ }^{6}$ O papel da Colonizadora Bertaso é fundamental nesse planejamento e traçado (ANTUNES, 2009, p.11). ${ }^{7}$ Enquetes aplicadas durante a primeira semana de novembro de 2019 a 30 usuários do Ecoparque, localizado no bairro Passo dos Fortes, entre a Rua John Kennnedy e a Avenida Getúlio Vargas, em área pericentral, portanto. ${ }^{8} \mathrm{~A}$ loja Havan foi inaugurada em Chapecó no ano de 2007. A chegada desta loja faz parte de um processo de entrada do grande capital comercial na cidade, junto com Casas Bahia, Magazine Luiza e Ponto Frio, a partir do ano de 2000. A expansão deste setor reforçou o papel de Chapecó na hierarquia urbana do Oeste Catarinense, em função da atração de clientes de toda a região. A abertura destas redes comerciais era anunciada pela
Caminhos de Geografia
Uberlândia-MG
v. 23, n. 85
fev./2022
p. $54-68$
Página 58 
Rua Benjamin Constant, e que se estende por uma superfície superior aos $800 \mathrm{~m}^{2}$ (Figura 1). Escutar música, tocar violão numa roda de amigos, praticar roller,skate ou $\mathrm{BMX}^{9}$, são práticas comuns dos jovens chapecoenses nesse espaço privado mas de acesso coletivo, principalmente à noite, quando a loja fecha suas portas.

Figura 1 - Chapecó - SC. Avenida Getúlio Vargas, pistas de skate e estacionamento da Havan

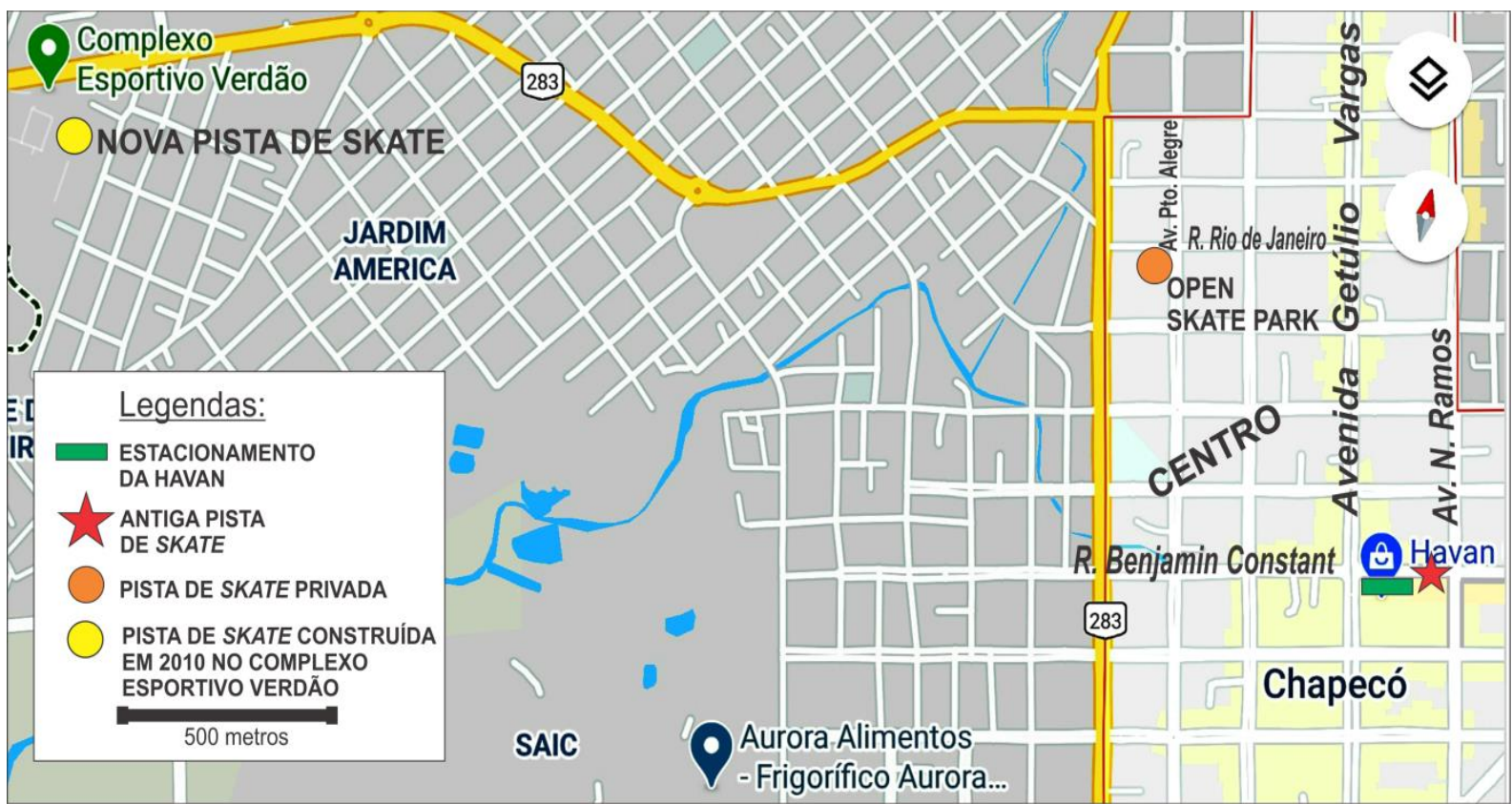

Fonte - Elaborado por Pablo Bender, baseado numa imagem do Google Maps, 2020

Mas estas práticas espaciais, corriqueiras e banais, realizadas no estacionamento privado de uma grande loja, portanto, revelando a potencialidade integrativa dos espaços de consumo (MAGRINI e CATALÃO, 2019), também podem ser entendidas como contestação (ou resistência) ao processo de transformação urbana que se iniciou com a revisão do Plano Diretor da cidade, no ano de 2006. As transformações que resultaram dessa revisão significaram uma profunda mudança na base popular do Plano Diretor de 2004, elaborado sob o governo municipal de Pedro Uczai (PT), e na política relativa aos espaços públicos até então vigente. Desde aquela revisão, e sob as diretrizes dos prefeitos João Rodrigues (DEM) e Luciano Buligon (PSL), entidades ligadas ao mercado imobiliário, à agroindústria e ao setor comercial, passaram a ter um peso superlativo na direção da política urbana de Chapecó (HASS, 2017; FACCO, FUJITA e BERTO, 2014).

Nesta nova correlação de forças, foi demolida em 2007, uma pista de skate que existia no antigo calçadão, sobre a rua Benjamin Constant, a poucos metros da depois inaugurada loja Havan, com o argumento de que a pista trazia perturbação ao sossego dos vizinhos. A projeção e construção da pista havia sido uma das prioridades do Orçamento Participativo de 2001. O local escolhido era representativo do interesse da juventude em ocupar espaços centrais da cidade, a fim de promover o lazer, a cultura, o esporte, ao mesmo tempo em que "ordenava" a prática do skate num espaço específico, fora das ruas e calçadas. Sobre os cimentos do antigo calçadão e da pista de skate, que tinha sido edificada no ano de 2003, durante o governo do mencionado prefeito Uczai, foi instalado um estacionamento (LIBERALI, 2019, p.28), o que também é expressão da disputa entre a "cidade do automóvel" e as "mobilidades ativas" que a Política Nacional de Mobilidade Urbana (2012), promulgada durante o Governo de Dilma Rousseff (PT), procurou promover.

Segundo Liberali (2019), antes da demolição, e apesar da deterioração e abandono à qual se encontrava submetida por parte do poder público, a pista de skate do calçadão era muito freqüentada,

imprensa e pelo discurso político como parte de um processo "modernizador" da cidade (GRETZLER e ALBA, 2009). Atualmente Havan tem mais duas lojas na cidade: uma na Avenida São Pedro e outra no Shopping Pátio Chapecó.

${ }^{9}$ BMX é uma modalidade do ciclismo.

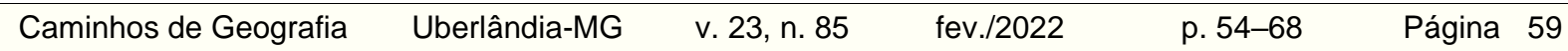


não somente por skatistas, senão também por praticantes de BMX, roller, artistas, bandas locais e jovens provenientes de toda a cidade, corroborando a importância de se identificar múltiplas e novas finalidades desse espaço público (SOUZA, 2018). Inclusive, no mesmo ano da demolição, foi organizado um campeonato regional de skate que congregou participantes de vários estados, com a finalidade de arrecadar fundos para conseguir arrumá-la. Mesmo assim, meses depois ela foi destruída e o estacionamento que ocupou seu lugar ficou pronto pouco tempo antes da inauguração da Havan (LIBERALI, 2019, p. 28).

Além de pista de skate, o antigo calçadão de Chapecó abrigava uma série de serviços, infraestrutura e pequenos comércios, como lanchonetes, banheiro público, floricultura e bancos, que favoreciam a sociabilidade, sendo o mesmo construído sobre a canalização do leito do rio Passo dos Índios (LIBERALI, 2019, p.18). Na frente do local onde se encontrava a antiga pista, entre as ruas Benjamin Constant e Av. Nereu Ramos, em 2019, podia se ler a pichação "Cadê a pista" (Figura 2):

Figura 2 - Chapecó - SC. Pichação (à esquerda) e reivindicação dos skatistas nas redes sociais (à direita)

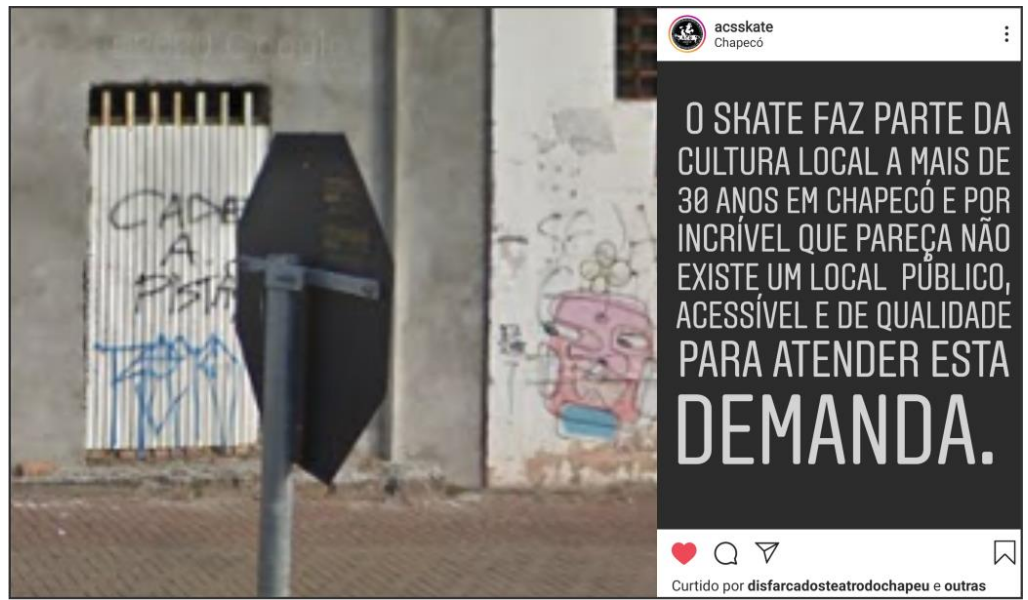

Fonte - Imagens tomadas do Google Street View, 2019, e do Instagram da Associação chapecoense de skate@acskate, postado no dia 03/10/2019.

Mas a destruição da pista e do calçadão, enquanto evidencias das tendências à homogeneização e diferenciação contrapostas ao direito de todos à cidade (SPOSITO e GÓES, 2013), não foi determinante para tirar os jovens dessa área central. Eles reagiram, ocupando o próprio estacionamento da Havan e suas proximidades para realizar suas práticas esportivas e sociais ${ }^{10}$. São numerosos os que aproveitam a estrutura plana do estacionamento para praticar esportes sobre rodas e é comum encontrar nele "batalhas de rap" e jovens escutando música com seus celulares ou pequenos aparelhos de som. Inclusive, o estacionamento é utilizado por crianças que, supervisionadas por seus pais, aprendem nele a andar de bicicleta (KESCHNER, 2017).

O processo de "ocupação" do estacionamento não foi consensual, nem esteve isento de conflitos, senão que suportou a reação dos agentes públicos e privados de segurança, com frequentes investidas policiais, sobretudo no período em que predominou a "lei seca" nos espaços públicos de Chapecó, à qual faremos referência mais adiante. A constância dos usuários e a falta de espaços alternativos delimitou, informalmente, uma nova mas instável territorialidade nesse espaço privado mas de acesso coletivo, em favor dos jovens (LIBERALI, 2019, p. 32; KESCHNER, 2017).

Em 2007, os praticantes de skate na cidade já estavam organizados na Associação de Skatistas de Chapecó (Chapecó SK8), entidade que em 2018 se transformara na Associação Chapecoense de Skate (ACS). Depois de muitas tratativas e protestos, conseguiram que em 2010, a prefeitura construísse uma nova pista, que foi projetada longe do centro, no Complexo Esportivo Verdão (Figura 1). Durante o trabalho de campo,numa quinta-feira à tarde, não encontramos nenhum praticante na pista, mas novas observações, em diferentes dias e horários, são necessárias.

${ }^{10}$ Além do estacionamento da Havan, outros espaços que viraram "points" de skatistas depois da destruição da pista foram a escadaria da Catedral e o palco da Praça Coronel Bertaso, ambas localizadas sobre a Avenida Getúlio Vargas (ANTUNES, 2009, p. 77; KESCHNER, 2017).

$\begin{array}{lllll}\text { Caminhos de Geografia Uberlândia-MG } & \text { v. 23, n. } 85 & \text { fev./2022 } & \text { p. 54-68 } & \text { Página } 60\end{array}$


Em contatos que mantivemos via Facebook e Instagram com um dos membros da Associação Chapecoense de Skate, foi comentado que a pista do Verdão não reúne as condições necessárias para praticar profissionalmente nenhuma modalidade do esporte, tendo sido construída por uma empresa não especializada. Ele também declarou que muitos skatistas têm que viajar a cidades vizinhas, onde a prática nem sequer é tão popular quanto em Chapecó, para fazer uso de pistas apropriadas ${ }^{11}$. A reivindicação de um espaço adequado ainda continua e ocorre nas redes sociais (Figura 2), inclusive com ações solidárias que publicam via Facebook e Instagram.

Em 2012, foi inaugurada uma pista de skate privada, a Open Skate Park, no centro de Chapecó (Figura 1), com cobrança de diárias ou mensalidades para seus usuários, além de venda de alimentos e bebidas, mas que no ano de 2017 fechou suas portas ${ }^{12}$, deixando aos praticantes desse esporte sem alternativas públicas, nem privadas.

Com base nas disputas, assim como nas novas relações estabelecidas entre espaços públicos e espaços privados, muito além de um processo de privatização, já amplamente constatado nas cidades brasileiras (CALDEIRA, 2000; SERPA, 2007), observamos que, através das práticas espaciais, movimentos diversos e, por vezes, contraditórios, estão presentes. Não basta postular que tudo mudou, mas é preciso identificar como esses processos operam espaços e tempos determinados, com sujeitos específicos. Se os jovens skatistas foram direcionados para fora do centro, com a demolição da "antiga" pista e construção de uma nova, a reapropriação que realizaram do estacionamento privado de acesso coletivo, enfrenta resistências, mas se mantém. Simultaneamente, a tentativa de tornar a prática do skate uma atividade lucrativa, foi frustrada, o que aponta limites da sua colonização pelo consumo, mesmo que relativos. Não menos significativo é o deslocamento do campo de atuação política da ACS para as redes sociais, ainda que suas implicações exigissem pesquisa específica.

\section{MESAS E CADEIRAS PÚBLICAS E PRIVADAS}

Em 2019, outra medida que tentou desestimular a sociabilidade de trabalhadores e jovens chapecoenses, além de afastá-los do centro, foi a retirada dos bancos e mesas do canteiro central da Avenida Getúlio Vargas, que poderia ser caracterizada como "destruição do espaço público", tal como observado por Davis (1993). Segundo Antunes (2009), que realizou pesquisa antes da retirada dos bancos, esse mobiliário era utilizado,ao meio dia, por funcionários das lojas que faziam seu almoço nele, e pela noite, por jovens que se reuniam para sociabilizar (ANTUNES, 2009, p. 53 e 75). O argumento para a retirada das mesas e bancos públicos foi a "segurança", e a ideia partiu, oficialmente, da Polícia Militar, sendo acatada pela Prefeitura Municipal. De acordo com o depoimento do Tenente da Polícia Militar, publicado num jornal da cidade, também as árvores, que dificultavam o monitoramento ${ }^{13}$, e o consumo de bebidas fora dos estabelecimentos comercias,configuravam um problema para a segurança pública no centro de Chapecó:

Nesses locais há problema de iluminação, as árvores escondem o videomonitoramento e as mesas contribuem para que eles (os jovens) tragam bebidas, drogas e façam o consumo sem entrar nos estabelecimentos comerciais. Isso faz com que os jovens permaneçam nestas áreas sombreadas, sentados, e não entrem nos ambientes. (...) com a presença da polícia nesses locais, a remoção dos bancos e mesas, a melhoria da iluminação pública e o corte das árvores, haverá mudanças significativas ${ }^{14}$.

A retirada dos bancos e mesas gerou uma série de comentários sobre a referida notícia do Jornal ClicRDC, contrários à remoção:

\footnotetext{
${ }^{11}$ Informações obtidas via mensagens através da página oficial de Facebook da Associação Chapecoense de Skate $(2 / 07 / 2020)$.

${ }^{12}$ Informação obtida da página de Facebook da Open Skate Park: OPEN Skate Park. Disponível em: $<$ https://www.facebook.com/openskatepark/about/?ref=page_internal>. Acesso: 02 jul. 2020. Atualmente, um edifício está sendo construído no espaço antes ocupado pela Open Skate Park, no âmbito do processo de verticalização e expansão do capital no centro de Chapecó.

${ }^{13}$ Chapecó possui um sistema de vigilância dos espaços públicos conformado por 183 câmeras que integram o Projeto Bem-te-vi.

${ }^{14}$ BANCOS E MESAS serão retirados do canteiro central da Getúlio Vargas. Depoimento do Tenente Coronel PM Ricardo Alves da Silva. Noticia online, Jornal Clic RDC, 18 de janeiro de 2019. Disponível em: $<$ https://clicrdc.com.br/categoria-geral/bancos-e-mesas-serao-retirados-do-canteiro-central-da-getulio-vargas/>. Acesso: 04 Jul. 2020.
} 
Só permanece em Chapecó o que favorece a elite, para o povão só interessa o voto e os impostos! E pra que serve a Guarda Municipal, a Policia Militar etc.? Para protegerem as empresas e os interesses da elite? (Alberto Santos Aguirre, 21/01/2019).

Sr. prefeito, nós gostamos de sentar fim de tarde nos bancos, eles enfeitam a cidade. Por favor não tire. O comandante do batalhão daqui a pouco sai e vem outro. Não mude o que nós achamos tão bonito para a cidade. A polícia que cuide da baderna. (Maria da Graça Coelho Pereira, 19/01/2019).

Perspectiva higienista! Interessante que a mesma prefeitura acaba de autorizar a usarem as calçadas para colocar suas mesas. Resumo: se você pagar para um estabelecimento privado, você pode usar o espaço público. Caso contrário fique em casa! (Everton, 18/01/2019).

Quase ao mesmo tempo em que o espaço público perdia mesas e cadeiras porque "os jovens fazem o consumo sem entrar nos estabelecimentos", novas normas favoreciam a privatização do espaço público das calçadas da Avenida Getúlio Vargas. Um mês antes da retirada dos bancos do canteiro central, o Prefeito Luciano Buligon (PSL), decretou as normas sobre colocação de mesas, cadeiras e playgrounds em bares e restaurantes das calçadas da avenida, com a possibilidade de ampliar esses espaços para áreas adjacentes, com prévia autorização. A nova norma estabelece uma faixa de circulação para pedestres de dois metros, enquanto que as mesas e cadeiras podem ocupar 1,5 metros a cada lado dessa via. O decreto impõe clara proibição de vender e expor produtos na calçada, com a intenção de inviabilizar o comércio ambulante na Getúlio Vargas ${ }^{15}$.

Conforme essa iniciativa, se bem o consumo de álcool em bares e restaurantes parece estar amparado e até ser promovido pelas normas oficiais, no espaço público sua ingestão foi (inconstitucionalmente) proibida e perseguida pela Prefeitura Municipal e pela Polícia Militar. Anteriormente, em 2014, o então prefeito José Cláudio Caramori (PSD) ${ }^{16}$ aprovou uma lei que impedia o consumo de bebidas alcoólicas nos espaços públicos de Chapecó, alegando "decorrentes transtornos causados por pessoas reunidas em logradouros públicos para o consumo de álcool"17.

Nos artigos 1 e 2, a "lei seca" em espaços públicos estabelecia que:

Art. 1 Fica proibido o consumo de bebidas alcoólicas de qualquer graduação em Logradouros Públicos do Município de Chapecó, Estado de Santa Catarina.

Art. 2ำ Para os efeitos desta Lei, são considerados Logradouros Públicos: I - as avenidas; II - as rodovias; III - as ruas; IV - as alamedas, servidões, caminhos e passagens; V - as calçadas; VI - as praças; VII - as ciclovias; VIII - as pontes e viadutos; IX - o hall de entrada dos edifícios e estabelecimentos comerciais que sejam conexos à via pública e que não sejam cercados; $\mathrm{X}$ - os pátios e estacionamentos dos estabelecimentos que sejam conexos à via pública e que não sejam cercados; XI - a área externa dos campos de futebol, ginásios de esportes e praças esportivas de propriedade pública; XII - as repartições públicas e adjacências ${ }^{18}$.

Em seu artigo 5ㅜㅡ, a lei outorgava faculdades à Polícia Militar para controlar a aplicação da normativa: "A autoridade policial que flagrar o descumprimento da Lei, determinará ao infrator que cesse a conduta, lavrando termo, tomando as medidas penais cabíveis em caso de descumprimento"19.Depois de estar em vigor por mais de três anos, a "lei seca" em espaços públicos de Chapecó foi declarada inconstitucional pelo Ministério Público de Santa Catarina, com base em dois argumentos principais. Primeiro, alegando haver "inconstitucionalidade formal",por ter o município legislado sobre a atribuição da Polícia Militar, sendo esta incumbência do Governador do Estado;segundo, se constatou "inconstitucionalidade material",no que se refere à proibição do consumo de bebidas alcoólicas em logradouros públicos ${ }^{20}$.

${ }^{15}$ Decreto № 36.181 , de 12 de dezembro de 2018, regulamenta a colocação transitória de mobiliário em passeios públicos por estabelecimentos comerciais e dá outras providências. Prefeitura de Chapecó, 2018.

${ }^{16}$ José Cláudio Caramori foi diretor da Associação Comercial e Industrial de Chapecó entre 2007 e 2008.

17TRIBUNAL de Justiça de Santa Catarina TJ-SC - Direta de Inconstitucionalidade: ADI 80002803020168240000 , Chapecó 8000280-30.2016.8.24.0000. Relator: Desembargador Ronei Danelli. Florianópolis, 4 dez. 2017. Disponível em:<https://ti-sc.jusbrasil.com.br/jurisprudencia/533869330/direta-de-inconstitucionalidade-adi80002803020168240000-chapeco-8000280-3020168240000/inteiro-teor-533869386>. Acesso, 20 jul, 2020.

18 Lei № 6555: de 07 de março de 2014. Dispõe sobre a proibição do consumo de bebidas alcoólicas em logradouros públicos do município de Chapecó e dá outras providências. Prefeitura de Chapecó, 2014.

${ }^{19}$ Nota 18

${ }^{20}$ Nota 11

$\begin{array}{llllll}\text { Caminhos de Geografia } & \text { Uberlândia-MG } & \text { v. 23, n. } 85 & \text { fev./2022 } & \text { p. 54-68 } & \text { Página } 62\end{array}$ 
A pesar de que a lei se devia aos supostos transtornos ocasionados no espaço público pelo consumo de álcool, os meios de comunicação divulgaram informações que revelam os interesses comerciais por trás daquela medida. No site da jornalista Olivete Salmória, podemos ler a seguinte informação:

Em Chapecó a Câmara de vereadores aprovou projeto de lei que proíbe o consumo de álcool nas vias públicas, de autoria do presidente da Câmara de Vereadores de Chapecó Marcio Ernani Sander, e recebeu integral apoio da Câmara de Dirigentes Lojistas de Chapecó (CDL). Na verdade, a reivindicação pela criação de norma legal municipal que proíba o consumo de bebidas alcoólicas em logradouros públicos foi uma reivindicação da própria CDL, apresentada pelo presidente José Carlos Benini. (SALMÓRIA, 05/07/2014)

O interesse econômico por trás daquela lei também foi exposto no Diário Catarinense:

O presidente da CDL Chapecó, José Carlos Benini, pediu maior rigor na aplicação da lei sancionada em março passado que proíbe o consumo de bebidas alcoólicas em vias públicas. A criação de uma norma legal municipal que proibisse o consumo de bebidas alcoólicas em logradouros públicos foi uma bandeira da própria CDL junto aos poderes Legislativo e Executivo. (LEI SECA, Diário Catarinense,13/08/2014)21.

À luz das evidencias expostas, podemos perceber que empresários do setor comercial e imobiliário tinham demandas sobre o espaço público, que foram veiculadas e atendidas pelo poder público municipal e pela Polícia Militar, inclusive por cima do direito expresso na Constituição Federal. Como decorrência, a proibição da presença dos vendedores ambulantes, especialmente na Avenida Getúlio Vargas, atingiu as estratégias de sobrevivência dos imigrantes ${ }^{22}$ e de outros "comerciantes informais" que lá atuavam "com papel preponderante" (ANTUNES, 2009, p. 62). Foi significativo que, durante o citado trabalho de campo que realizamos em 11/2019, verificamos que estas atividades estavam quase ausentes na avenida. Além disso, a retirada de mesas e bancos prejudicou os trabalhadores que neles repousavam na hora do almoço, enquanto que os jovens moradores da periferia insistem em frequentar o centro da cidade e ali realizar suas práticas espaciais.

Nessa disputa, normas e repressão são empregados pelos primeiros agentes mencionados, enquanto práticas de resistência no espaço vão re-significando lugares com usos que confrontam as normas e propõem alternativas criativas à "destruição" do espaço público, mesmo que temporárias, por vezes fugazes, o que evidencia a necessária atenção às relações entre espaço e tempo, para sua compreensão. Algumas destas relações espaço-temporais "alternativas" foram destacadas por Antunes (2009, p. 137), quando analisou as formas pelas quais os jovens ocuparam diferentes setores da avenida, conforme a noite avançava, ou quando elaboraram estratégias para evitar ser "pegos" na "seleção não democrática da fiscalização", numa blitz.

Buscando ir além dessas análises, levamos em conta as relações entre a escala local e a nacional, seja para compreender a novas dimensões legais (ou jurídicas) que influenciam na gestão e nos usos dos espaços públicos, seja para identificar as conexões entre a escala local e a global promovidas através das práticas espaciais dos skatistas. Assim, a interescalaridade, que diferencia os processos de fragmentação e segregação socioespacial (SPOSITO e GÓES, 2013, cap.11), caracterizando o primeiro apenas, pode ser uma das evidências de que tal processo esteja se introduzindo em Chapecó nas últimas duas décadas. Mas não é possível apoiar-se em uma evidência apenas. É necessário considerar também a supervalorização da insegurança, a privatização de espaços e práticas, o novo papel do consumo, o qual mudou de intensidade e conteúdo, bem como de status, conformando o mundo e se associando à tendência de individualização da experiência e aos processos de diferenciação (BOURDIN, 2005), identificados a partir do contexto descrito em Chapecó e que são característicos do processo de fragmentação socioespacial, segundo Sposito e Góes (2013).

Além disso, a influência da "nova razão do mundo", representada pelo neoliberalismo (DARDOT e LAVAL, 2016), está presente e deve ser levada em conta, sobretudo, em função da atuação do Estado, aí representado pela Prefeitura Municipal, a serviço dos interesses econômicos, explicitamente. Os "programas" elaborados pela prefeitura que analisaremos em seguida, ampliam tal atuação, uma vez

${ }^{21}$ LEI SECA, Diário Catarinense, notícia online. Publicada no dia 13 de agosto de 2014. Disponível em: <http://wp.clicrbs.com.br/visor/2014/08/13/lei-seca/?topo=67,2,,777>Acesso: 05 jul. 2020.

${ }^{22}$ Durante o trabalho de campo, em entrevista com o Presidente da Associação de Haitianos de Chapecó, Sr. Nahum Saint Jullien (5/11/2019), soubemos das dificuldades iniciais enfrentadas pelos imigrantes que chegam à cidade, em função da atração exercida pelas agroindústrias. Nos 6 meses que demanda a tramitação da carteira de trabalho e o visto, eles precisam realizar alguma atividade econômica para sobreviver, como é o caso do comércio ambulante.

$\begin{array}{llllll}\text { Caminhos de Geografia } & \text { Uberlândia-MG } & \text { v. 23, n. } 85 & \text { fev./2022 } & \text { p. 54-68 } & \text { Página } 63\end{array}$


que tendem a reforçar os mecanismos privados de gestão do espaço público de maneira direta, configurando novas tendências nas relações público - privado.

\section{A "ADOÇÃO" DE ESPAÇOS PÚBLICOS}

Entre os "programas" que estabelecem novas formas de produção e gestão do espaço público, destacamos àquele que permite a "adoção" de praças e parques por parte de empresas ou pessoas físicas, em troca de propaganda. A Lei foi promulgada sob o contexto do Programa Chapecó Mais Bonita, em 2007, e nela se estabelece que:

Fica instituído o "PROGRAMA CHAPECÓ MAIS BONITA", que visa compartilhar com a comunidade, através de pessoas físicas ou jurídicas, organizações não governamentais ou entes legalmente constituídos, praças, canteiros centrais e laterais das vias públicas, áreas verdes, monumentos e outros espaços públicos municipais livres. ${ }^{23}$

A construtora e incorporadora imobiliária "Nostra Casa", uma das mais importantes do setor em Chapecó, é a empresa que mais tem adotado espaços públicos, todos localizados em áreas centrais e com boa infraestrutura, sendo que alguns deles exercem papel de valorização das fachadas de seus próprios condomínios verticais. Um dos espaços públicos mais importantes adotado pela empresa é a praça localizada em frente da Arena Condá, em memória dos falecidos no acidente aéreo da Chapecoense de 2016, e que leva o nome do fundador da empresa: "Átrio Daví Barela Dávi"24. Conforme foi observado no trabalho de campo, no marco desta lei, algumas pessoas físicas também se organizaram para manter limpos e cuidados os canteiros centrais que ficam na frente das suas casas ou apartamentos (Figura 3).

Figura 3 - Chapecó - SC. Localização de espaços públicos "adotados" no Programa Chapecó Mais Bonita.

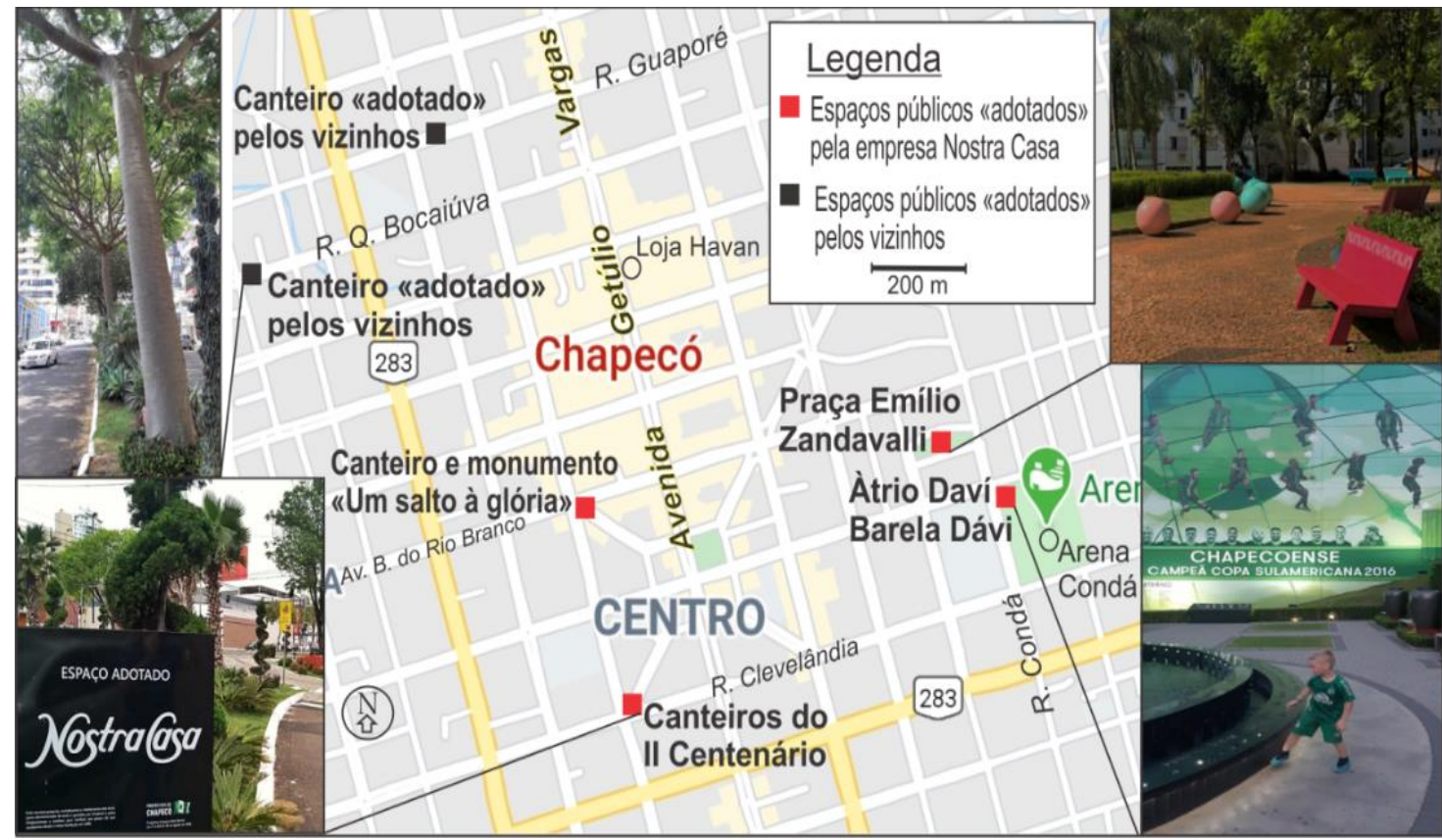

Fonte - Elaborado por Pablo Bender, baseado em imagem do Google Maps. Fotos: Pablo Bender, 2019.

Já em 2019, foi criado um programa similar ao "Chapecó mais Bonita", denominado "Adote um bem cultural", oficialmente destinado a propiciar à iniciativa privada, a possibilidade de "cooperar com o Poder Público" na restauração, preservação ou conservação, de bens culturais e edifícios públicos, conforme estabelece a lei:

${ }^{23}$ Lei N ${ }^{\text {o }} 5239$, de 28 de agosto de 2007, dispõe sobre a instituição do Programa Chapecó mais bonita e dá outras providências. Câmara Municipal, Chapecó, 2007.

${ }^{24}$ Daví Barela Dávi faleceu no mesmo acidente.

\begin{tabular}{|c|c|}
\hline Caminhos de Geografia & Uberlândia-MG \\
\hline
\end{tabular}


Para efeitos de interpretação da presente Lei, adotam-se os seguintes conceitos:

I - Bem Cultural, todos os bens móveis ou imóveis, que apresentem uma grande importância para o patrimônio cultural do povo chapecoense, tais como os monumentos de arquitetura, de arte ou de história, os conjuntos de construções, as obras de arte, os manuscritos, arquivos, livros e outros objetos, de interesse artístico, histórico ou arqueológico, assim como as manifestações culturais imateriais protegidas pela Administração Municipal, por meio dos instrumentos do tombamento, registro ou guarda de acervo histórico.

II - Equipamentos culturais, os bens imóveis destinados à programas, projetos, atividades e ações culturais do Município, como os teatros, biblioteca, museus, centros culturais, galerias e exposições artístico-culturais, dentre outros, vinculados à Secretaria de Cultura. ${ }^{25}$

Pouco antes disso, em 2018, outra das ações que levou adiante a prefeitura de Chapecó, tentando estabelecer novas parcerias público/privadas, foi o programa "Minha rua mais bonita", que permite aos vizinhos se associarem a uma empresa privada para pavimentar as ruas de seu bairro. A lei que possibilita a contratação direta de empresas privadas, por vizinhos, para a construção de ruas e calçadas, estabelece no seu artigo 2 o seguinte:

2ำ Ficam autorizados os proprietários ou possuidores de imóveis, a promoverem a contratação direta de empresa permissionária para a execução de obras de pavimentação e serviços complementares de infraestrutura urbana em vias públicas do município, conforme disposições desta Lei. ${ }^{26}$

Para a contratação da empresa, a totalidade dos vizinhos devem estar de acordo e arcar com o custo da obra. Apesar de que a promulgação desta lei foi anunciada como uma forma de desburocratizar as ações e acelerar a execução de obras de pavimentação, num levantamento feito na mídia digital da cidade, encontramos que só dois trechos de ruas haviam sido pavimentados com esta modalidade desde sua criação, fato que coloca em questão a efetividade deste tipo de política "pública".

Além disso, não podemos desconsiderar que se trata de uma estratégia do poder público municipal de transferir para a iniciativa privada, responsabilidades que são suas, relacionadas à manutenção do espaço público. Quais as suas implicações? Numa cidade caracterizada pela intensa desigualdade socioeconômica entre moradores do centro e da periferia, tal transferência promove a radicalização das condições já diferenciadas dos respectivos espaços, uma vez que as possibilidades de "contratação de empresa permissionária para a execução de obras" apenas estariam presentes no primeiro, portanto,é das díspares correlações de forças "que conduzem os destinos da cidade", a favor da reprodução do capital (SPOSITO e SPOSITO, 2020, p. 6; LEFEBVRE, 2001) que se trata.

A baixa efetividade da lei também pode ser explicada pelas características inerentes ao neoliberalismo, que se diferencia do liberalismo, entre outros aspectos, pelo fato de não implicar numa redução da atuação do Estado, mas sim na sua instrumentalização pelos interesses privados, especialmente dos grandes capitais (DARDOT e LAVAL, 2016). Nas cidades latino-americanas, o papel do Estado sempre foi fundamental (PRÉVÔT-SCHAPIRA, 2001), portanto, a própria proposição de uma legislação dessa natureza é expressiva das mudanças que vêm ocorrendo numa escala global e que tendem a afetar o reconhecimento de todos à cidade, especialmente representado pelo acesso aos seus espaços públicos.Se as relações entre a escala local e a global são evidentes e corroboram tendências dos processos de produção do espaço urbano, como a fragmentação socioespacial, há disputa, como demonstramos ao longo desse artigo.

\section{CONSIDERAÇÕES FINAIS}

Com base nos recortes e hipóteses propostas, pudemos compreender algumas das principais problemáticas urbanas referentes à produção do espaço público em Chapecó, que longe de ser um processo linear, se manifesta como dialético e em construção. Neste processo, mediante disputas entre sujeitos muito desiguais, as relações entre espaços públicos e espaços privados vão sendo alteradas, seja pelas práticas de sociabilidade, como no caso da ocupação do estacionamento da Havan, seja por

25Lei № 7.242, de 13 de junho de 2019, cria o Programa "ADOTE UM BEM CULTURAL", no âmbito do Município de Chapecó, por meio de parcerias público-privadas e dá outras providências. Prefeitura de Chapecó, 2019.

${ }^{26}$ Lei № 7143, de 14 de maio de 2018, institui o Programa de Pavimentação Minha Rua Mais Bonita e dá outras providências. Câmara Municipal, Chapecó, 2018.

$\begin{array}{llllll}\text { Caminhos de Geografia } & \text { Uberlândia-MG } & \text { v. 23, n. } 85 & \text { fev./2022 } & \text { p. 54-68 } & \text { Página } 65\end{array}$


medidas legais, implementadas, não efetivadas ou revertidas, como no caso do revés judicial que recebeu a prefeitura em relação à proibição do consumo de álcool nos espaços públicos. Todas essas evidências, baseadas no exame das condições objetivas de produção de espaços reais, problematizam as assertivas excessivamente generalistas e abstratas sobre a "crise" (CALDEIRA, 2000) ou "morte" (SENNETT, 1999, p. 26) do espaço público.

Numa outra interpretação, baseada na ideia de disputa, demonstramos que à "destruição" (DAVIS, 1993) do espaço público,proposta pelo setor empresarial e político conservador, numa conjuntura política específica,se contrapuseram práticas que superaram de maneira criativa a negação do direito à cidade. A noção de "terceiro espaço" de Soja (1996) e a interpretação de Crawford (2014) e Souza (2018), tem a ver com essa possibilidade de resposta "inesperada" que o espaço pode brindar, transformando-se através de práticas inovadoras em um lugar novo, mesmo que de modo intermitente, que é fruto da imaginação e também da necessidade; no caso discutido nesse artigo, de lazer e sociabilidade. Estas circunstâncias demonstram que existem múltiplas "esferas públicas" que condicionam a política (DEUTSCHE, 2018), assim como as intrínsecas relações entre a dimensão construída, a política e social desses espaços (GOMES, 2002).

Temos indícios de que o uso do espaço público no centro de Chapecó se caracteriza por temporalidades diferenciadas, sendo ocupado pelos jovens da periferia nos finais de semana, os quais se tentou afastar através de medidas restritivas, enquanto que é utilizado predominantemente pelas classes médias e altas nos demais dias de semana. Neste sentido, estaria em curso um processo de fragmentação socioespacial mais sutil e menos visível que àquele materializado em muros que separam às classes sociais em outras cidades do Brasil, mas,nem por isso, menos eficaz.A fragmentação socioespacial em Chapecó estaria principalmente relacionada com a dimensão normativa e simbólica (MAGRINI e CATALÃO, 2029), mesmo que não desconsideremos a "materialidade" que implicou a destruição e retirada de mobiliário urbano para lazer, sociabilidade e esporte do centro da cidade.

Mas é preciso continuar pesquisando, inclusive direcionando maior atenção para os espaços periféricos de Chapecó, uma vez que a relação centro - periferia foi complexificada, mas não superada pelo processo de fragmentação socioespacial, cujas evidências debatemos nesse artigo.

\section{REFERÊNCIAS}

ANTUNES, Camila. Do passeio na avenida à balada no prolonga: sociabilidade no espaço público: o caso da Avenida Getúlio Vargas, Chapecó (SC). 2009. 152 f. Dissertação (Mestrado em Antropologia Social) -Centro de Filosofia e Ciências Humanas, Universidade Federal de Santa Catarina, Florianópolis,2009. Disponível em: <https://repositorio.ufsc.br/handle/123456789/92348>. Acesso: 5 jul. 2020.

ARAMBURU, Mikel. Usos y significados del espacio público. ACE: Arquitectura, Ciudad y Entorno, Barcelona, ano III, núm. 8, p. 143-151, out. 2008. Disponível em: $<$ https://upcommons.upc.edu/handle/2099/6586 >. Acesso: 3 jul. 2020. https://doi.org/10.5821/ace.v3i8.2461

ARENDT, Hannah. A condição humana. Rio de Janeiro: Forense Universitária, 2008.

BLANCO, Gabriel. Loteamentos fechados, condomínios fictícios.2011. 202 p. Dissertação (Mestrado em Direito) - Pontifícia Universidade Católica de São Paulo, São Paulo, 2011. Disponível em: <https://tede2.pucsp.br/handle/handle/5711>. Acesso: 10 jul. 2020.

BOURDIN, Alain. La métropole des individus. Paris: Éditions de l'Aube, 2005.

CALDEIRA, Tereza. Cidade de muros: Crime, segregação e cidadania em São Paulo. São Paulo: Ed.34-Edusp, 2000.

CRAWFORD, Margaret. Difuminando los límites: espacio público y vida privada. In: RAMOS, Angel (org). La calle moderna, en $\mathbf{3 0}$ autores contemporáneos y un pionero. Barcelona: UPB, 2014, p. 123-130.

DARDOT, Pierre; LAVAL, Christian. A nova razão do mundo. São Paulo: Boitempo, 2016.

DAVIS, Mike. Cidade de quartzo: escavando o futuro em Los Angeles. São Paulo: Scritta, 1993.

DEUTSCHE, Rosalyn. Agoraphobia. In: MAGALHÃES, Elisa de, MARTINS, Tatiana (org.) Arte \&

Ensaios, n. 36, p. 116-173, Rio de Janeiro, Programa de Pós-Graduação em Artes Visuais/ Escola de

$\begin{array}{lllll}\text { Caminhos de Geografia } & \text { Uberlândia-MG } & \text { v. 23, n. } 85 & \text { fev./2022 } & \text { p. 54-68 }\end{array}$ Página 66


Belas Artes, UFRJ, dez. 2018. Disponível em:

$<$ https://revistas.ufri.br/index.php/ae/article/download/22485/12769>. Acesso: 20 jul. 2020.

DUHAU, Emilio; GIGLIA, Ángela. Espacio público y nuevas centralidades. Dimensión local y urbanidad en las colonias populares de la Ciudad de México. Papeles de Población, vol. 10, núm. 41, p. 167 - 194, jul/set, 2004.Disponívelem:

$<$ http://www.scielo.org.mx/scielo.php?script=sci abstract\&pid=S1405-

74252004000300006\&lng=es\&nrm=iso $>$. Acesso: 4 jul. 2020.

Las reglas del desorden: habitar la metrópoli. México DF: Siglo XXI Editores - Universidad Autónoma Metropolitana- Azcapotzalco, 2008.

FACCO, Janete. FUJITA, Camila. BERTO, James Luiz. Agroindustrialização e urbanização de Chapecó-SC - Brasil (1950 - 2010): uma visão sobre os impactos e conflitos urbanos e ambientais.

REDES - Revista de Desenvolvimento Regional, Santa Cruz do Sul, v. 19, n. 1, p. 187 - 215 , jan/abr 2014. Disponível em: <https://online.unisc.br/seer/index.php/redes/article/view/2481>. Acesso: 10 jul. 2020.

GABARDO, Emerson. O princípio da supremacia do interesse público sobre o interesse privado como fundamento do Direito Administrativo Social. Revista de Investigações Constitucionais, Curitiba, vol. 4, n. 2, p. 95-130, maio/ago. 2017. Disponível em:

$<$ https://revistas.ufpr.br/rinc/article/view/53437/33212>. Acesso: 05 jul. 2020.

https://doi.org/10.5380/rinc.v4i2.53437

GOMES, Paulo César da Costa. A Condição Urbana - Ensaios de Geopolítica da Cidade. Rio de Janeiro: Bertrand Brasil, 2002.

GRETZLER, Cristiane; ALBA, Rosa. A entrada das grandes redes de lojas em Chapecó a partir do ano de 2000 e as repercussões na reorganização urbana da cidade. In: $12^{\circ}$ Encuentro de Geógrafos de América Latina, Caminando en una América Latina en transformación, Montevidéu, 2009. Anais, Montevidéu, 2009, p. 1-15. Disponível em:

$<$ http://observatoriogeograficoamericalatina.org.mx/egal12/Geografiasocioeconomica/Geografiaurban a/221.pdf $>$. Acesso: 10 jul. 2020.

GROSSELI, Carliana. O processo de verticalização da cidade de Chapecó/SC: 2010 a 2017. 2020. 153 f. Dissertação (Mestrado em Geografia) - Universidade Estadual do Oeste do Paraná, Francisco Beltrão, 2020. Disponível em: <http://tede.unioeste.br/handle/tede/4842>. Acesso: 04 set. 2020.

GUARANA, Maria Cristina. Direito público: os aspectos dos direitos constitucional, administrativo e tributário. Revista de metrologia legal. Rio de janeiro, №. 9, maio de 2009, p. 1-27. Disponível em: $<$ http://www.inmetro.gov.br/producaointelectual/obras intelectuais/264 obralntelectual.pdf $>$. Acesso: 5 jul. 2020.

HABERMAS, Jürgen. Mudança estrutural da esfera pública. Rio de Janeiro: Tempo Brasileiro, 2003.

HASS, Mônica. A governança no processo de discussão do plano Diretor de Desenvolvimento Territorial de Chapecó. In: NASCIMENTO, Ederson; VILLELA, Ana (org). Chapecó em foco: textos e contextos sobre o espaço urbano regional. São Carlos: Pedro \& João Editores, 2017.

INNERARITY, Daniel. O novo espaço público. Lisboa: Ed. Teorema, 2010.

JACOBS, Jane. Morte e vida de grandes cidades. São Paulo: Editora WMF Martins Fontes, 2011.

KESCHNER, Bruna. Espaços (semi) públicos de sociabilidade juvenil em Chapecó. 2017. $49 \mathrm{f}$. TCC (Graduação). Licenciatura em Geografia - Universidade Federal da Fronteira Sul: Chapecó, 2017. Disponível em: <https://rd.uffs.edu.br/bitstream/prefix/1436/1/KESCHNER.pdf>. Aceso: 3 jul. 2020.

MAGRINI, Angélica, CATALÃO, Igor. Direito à cidade e consumo: Contradições e convergências. In: GÓES, Eda et. al. Consumo, Crédito e direito à cidade: Curitiba, Appris, 2019.

MATIELLO, Alexandre Mauricio; VILLELA, Ana Laura Vianna, FUJITA, Camila; OTSUSCHI Cristina, ALBA, Rosa Salete. Chapecó/SC: o agronegócio, o setor terciário em expansão e a crescente desigualdade socioespacial. In: SPOSITO, Maria Encarnação B.; MAIA, Doralice S. (orgs). Agentes econômicos e reestruturação urbana e regional: Dourados e Chapecó. São Paulo: Cultura Acadêmica, 2017. 
MAIA, Claudio; SILVA, Gabriela; ALMEIDA, Julio. Os parques urbanos e sua função social: subsídios para a elaboração de políticas públicas. 9 Seminário Internacional sobre Desenvolvimento Regional: Processos, Políticas e Transformações Territoriais. Anais eletrônicos, Santa Cruz do Sul, RS, Brasil, 11 a 13 de setembro de 2019, p. 1-19.Disponível em: <https://online.unisc.br/acadnet/anais/index.php/sidr/article/view/18945>. Acesso: 2 jul. 2020.

NAVEZ-BOUCHANINE, Françoise. Emergence d'une notion: quelquesrepèreshistoriques. In: NAVEZBOUCHANINE, Françoise. La fragmentation en question: des villes entre fragentationspatialeetfragmentationsociale. Paris: L'Harmattan, 2002, p. 19-103.

LEFEBVRE, Henri. Metaphilosophie. Paris: Édition Syllepse, 2000.

O direito à cidade. São Paulo: Centauro, 2001.

LIBERALI, Guilherme. Cadê a pista? Skate e gentrificação na cidade de Chapecó-SC, 2007. 2019. 44 f. TCC (Graduação). 2019. 44 f. Licenciatura em História- Universidade Federal da Fronteira Sul: Chapecó, 2019. Disponível em: <https://rd.uffs.edu.br/handle/prefix/3499>. Acesso: 30 jul. 2020.

PRÉVÔT-SCHAPIRA, Marie-France. Fragmentación espacial y social: conceptos e realidades. Perfiles Latinoamericanos, FLCS, DF - México, n.19, p. 33-56, dez. 2001.

RAMMÉ, Juliana. Determinação de indicador de prioridade para manutenção e reestruturação das praças públicas em cidades de médio porte. 2014. 217 f. Dissertação (mestrado) - Programa de Pós-Graduação em Engenharia Civil, Universidade Federal de Santa Catarina, Florianópolis, 2014. Disponível em: <https://repositorio.ufsc.br/xmlui/handle/123456789/123172>. Aceso: 2 jul. 2020.

SABATIER, Bruno. Aportaciones del derecho al análisis geográfico de las sucesivas realidades del espacio público. Tradução de Josefina Anaya. Revista Trace, № 42, dez. 2002, p. 79-88. Disponível em: <http://trace.org.mx/index.php/trace/article/view/537/517>. Acesso: 10 jul. 2020. https://doi.org/10.22134/trace.42.2002.537

SALMÓRIA, Olivete: Ruas sem álcool. Blog de notícias: Olivete Salmória. Lages, 6 de março de 2014. Disponível em: <http://olivetesalmoria.com.br/12237-ruas-sem-alcool/>. Acesso: 05 jul. 2020.

SANTOS, M. A natureza do espaço: técnica e tempo, razão e emoção. São Paulo: Ed. Hucitec, 1996.

SENNETT, Richard. O Declínio do Homem Público: as tiranias da intimidade. São Paulo: Companhia das Letras, 1999.

SERPA, Angelo. O espaço público na cidade contemporânea. SP: Contexto, 2007.

SILVA, Antonio Marcos de Sousa. Estado, monopólio da violência e policiamento privado: com quem fica o uso legítimo da força física na sociedade contemporânea? Revista Emancipação, Programa de Pós Graduação em Ciências Sociais Aplicadas. Ponta Grossa, № 8: p. 9-19, 2008. Disponível em: $<$ https://revistas2.uepg.br/index.php/emancipacao/article/view/120>. Acesso: 11 jul. 2020.

SOJA, Edward. Third space: journays to Los Angeles and other real-and-imagined places. Cambridge: Blackwell, 1996.

SPOSITO, Eliseu S.; SPOSITO, Maria Encarnação B. Fragmentação socioespacial. Mercator, Fortaleza, v.19, p 1-12, jun. 2020. Disponível em: <http://www.mercator.ufc.br/mercator/article/view/e19015> Acesso: 10 jul. 2020. https://doi.org/10.4215/rm2020.e19015

SPOSITO, Maria Encarnação Beltrão; GÓES, Eda Maria. Espaços fechados e cidades: insegurança urbana e fragmentação socioespacial. São Paulo: Editora Unesp, 2013.

SOUZA, Andre F. Os espaços públicos nas cidades contemporâneas: um (re)visão. Geografares: Revista do Programa de Pós-Graduação em Geografia e do Departamento de Geografia da UFES, p. 182-213, Jul-Set, 2018. Disponível em: <https://periodicos.ufes.br/geografares/issue/archive> Acesso: 10 jul. 2020. https://doi.org/10.7147/GEO26.21005

WEBER, M. Ensaios de sociologia. 5e ed. Rio de Janeiro: Zahar, 1982.

Recebido em: 16/09/2020

Aceito para publicação em: 25/01/2021 